\title{
Ecoturismo étnico no Parque Nacional do Monte Pascoal: formas de comunicação entre condutores indígenas e visitantes da Unidade de Conservação
}

\author{
Ecotourism Ethnic in Monte Pascoal National Park: forms of communication \\ between indigenous guide and visitors to the protected area
}

\section{Carlos Alfredo Ferraz de Oliveira}

\begin{abstract}
RESUMO
$\mathrm{Na}$ aldeia do Pé do Monte, localizada na portaria do Parque Nacional do Monte Pascoal, no extremo sul da Bahia, vivem índios que atuam como condutores indígenas do parque com a função de guiar e informar os visitantes a importância desta área natural e suas relações histórico e culturais com a unidade de conservação. Este artigo tem o objetivo de descrever brevemente o contexto sociocultural da etnia Pataxó no extremo sul da Bahia e identificar as formas de comunicação dos condutores indígenas do Parque Nacional do Monte Pascoal. A pesquisa foi realizada através de estudo bibliográfico do histórico sociocultural dos Pataxós na região, entrevista semi estruturada com liderança indígena da aldeia do Pé do Monte, observação participante dos trabalhos dos condutores indígenas e análise do conteúdo dos dados coletados. Ao final da pesquisa foi possível identificar a narrativa, o artesanato, a arte plástica e rituais como formas de comunicação utilizadas pelos condutores indígenas com os visitantes. Verificou-se que durante a função de condutor, estes indígenas expressam suas lutas sociais e que o ecoturismo étnico é um meio de oportunizar a manifestação de antigas e novas tradições Pataxó ao visitante, como também o fortalecimento de sua etnia.
\end{abstract}

PALAVRAS-CHAVE: Comunicação Popular; Ecoturismo Étnico; Etnia Pataxó.

\begin{abstract}
In the Monte Pascoal National Park, indigenous guides from the Pataxó Indian settlement of Pé do Monte, located at the park entrance, inform visitors about the importance of this natural area and its historical and cultural relationship with the conservation unit. The purpose of this article is to briefly describe the sociocultural context of the Pataxó ethnic group in the extreme south of Bahia and to examine the forms of communication employed by the park's indigenous guides. The research was conducted through bibliographical study of the sociocultural history of the Pataxós in the region, a semi-structured interview with the Indian leader of the Pé do Monte settlement, participatory observation of indigenous guide work and content analysis of the collected data. Guides were found to communicate with visitors by way of visual art, crafts, ritual as well as verbal narrative. The research establishes that in the course of their work, the guides exteriorize their indigenous social struggles, and that ethnic ecotourism favours the expression of Pataxó traditions both new and old while reinforcing their ethnic identity.
\end{abstract}

KEYWORDS: Popular Communication; Ethnic Ecotourism; Ethnic Pataxó. 
Ecoturismo étnico no Parque Nacional do Monte Pascoal: formas de comunicação entre condutores indígenas e visitantes da Unidade de Conservação.

\section{Introdução}

O Parque Nacional do Monte Pascoal (PNMP) é uma Unidade de Conservação (UC) federal de proteção integral, aberta para visitação, localizada no município de Porto Seguro'. Esta UC possui um dos principais fragmentos remanescentes de Mata Atlântica do nordeste brasileiro, apresentando uma grande biodiversidade presente em quatro ecossistemas: Ombrófila Densa, Mussununga, Restinga e Manguezal (ISA, 2004). Além dos aspectos naturais o PNMP possui um contexto de importância histórica e sociocultural no cenário nacional, envolvendo comunidades indígenas e atividades turísticas.

As atividades de visitação realizadas no PNMP envolvem trilhas interpretativas e de subida ao Monte Pascoal, Centro de Visitantes, observação e vivência das manifestações culturais indígenas Pataxós.

Na portaria do PNMP encontra-se a aldeia do Pé do Monte que faz jus ao seu nome, pois se situa ao pé do Monte Pascoal, nome dado ao cume da formação geológica local que simboliza, no imaginário brasileiro, o marco da chegada dos portugueses no Brasil. A aldeia conta com cerca de 20 famílias da etnia Pataxó, que têm como um dos ofícios diários, a operacionalização das atividades de visitação no PNMP. A visitação nesta área é gerida em um processo de gestão compartilhada, através do Grupo de Trabalho de Ecoturismo (GTE), constituído por representantes da liderança indígena Pataxó, do Instituto Chico Mendes de Conservação da Biodiversidade (ICMBio) e da Fundação Nacional do Índio (FUNAI). Este GTE tem como objetivos a serem conquistados através das atividades de visitação do PNMP: o desenvolvimento do ecoturismo ${ }^{2}$, o esclarecimento e sensibilização do visitante sobre a importância social, ambiental e cultural da área, a geração e distribuição de renda aos Pataxós, o fortalecimento sociocultural das aldeias indígenas Pataxó localizadas no entorno da UC (OLIVEIRA, 2008).

Toda visitação realizada no interior do PNMP é acompanhada por um ou mais condutores indígenas Pataxós da aldeia do Pé do Monte, desde as primeiras informações ao visitante na portaria à interpretação ambiental das trilhas, monumentos e manifestações culturais observadas e vivenciadas.

Os condutores indígenas Pataxós desta localidade trabalham a interpretação ambiental expressando o seu contexto sociocultural, relacionado ao patrimônio natural da UC. Esta expressão é feita através da comunicação popular desta comunidade, compreendida como as manifestações culturais tradicionais Pataxó, associadas às suas resistências sociais e populares (PERUZZO, 1995).

A história dos índios Pataxós no extremo sul da Bahia é uma trajetória de lutas por território, abusos e descasos das autoridades governamentais, violência física e sociocultural, repressão e esquecimento cultural, atrações turísticas, reconstrução e criação de elementos culturais tradicionais (GRÜNEWALD, 2001; SAMPAIO, 2000).

Este trabalho visa descrever brevemente o histórico sociocultural da aldeia do 
Pé do Monte e sua relação com desenvolvimento do ecoturismo étnico na UC, e identificar as formas de comunicação popular, utilizadas pelos condutores indígenas Pataxós desta aldeia durante a visitação do PNMP, para apresentar aos visitantes sua historia étnica nesta região do Brasil.

\section{Procedimentos metodológicos}

A pesquisa foi realizada através de uma abordagem metodológica interpretativa (JONES, 1993) utilizando técnicas qualitativas para coleta e análise dos dados (MINAYO, 2004).

Inicialmente foi realizado um estudo bibliográfico (GIL, 1987) sobre o histórico da aldeia do Pé do Monte. Junto a este levantamento foi feita uma entrevista semi estruturada (JONES, 1993) com o cacique da aldeia, com a finalidade de dar voz a população pesquisada e verificar e complementar os dados levantados, principalmente as informações sobre a aldeia do Pé do Monte.

Para identificar a comunicação popular utilizada pelos condutores indígenas do PNMP, durante a visitação na área, foi necessário formatar um roteiro de observação que focasse as formas de expressões culturais utilizadas. Nesta categoria de análise foram destacados os seguintes indicadores: meios de comunicação (verbal, corporal, musical, artístico); objetivos e contexto sociocultural da mensagem.

A técnica de observação utilizada foi observação participante (STACEY, 1977; JONES, 1993) que tem a finalidade de coletar dados através do contato direto com o universo pesquisado. Durante as observações os dados foram registrados em gravador de voz digital e diário de campo visando facilitar a análise.

A observação participante foi aplicada nos seguintes atrativos e locais do PNMP: trilha da subida do Monte, Monumento da Resistência, locais de venda do artesanato Pataxó e apresentação do Awê. Sendo estes os indicados pelo cacique entrevistado como os principais e mais visitados.

Os dados coletados foram sistematizados e descritos proporcionando fazer uma relação do histórico da aldeia do pé do monte com as formas de comunicação utilizadas pelo condutor.

\section{Resultados e Discussão}

\section{Aspectos conceituais: Pataxó e manifestações étnico culturais no ecoturismo}

De acordo com Grünewald (2001) e Sampaio (2000), a criação em 1961, do PNMP expropriou uma população indígena da etnia Pataxó de seu território, no extremo sul da Bahia. Este fato apenas fortaleceu outros históricos de violência e descaso com esses indígenas, como "fogo de $51^{\text {"3 }}$ que assassinou e violentou diversos Pataxós, inclusive mulheres, e o contato conflitante com os portugueses séculos atrás.

Durante estes ocorridos, os Pataxós conseguiram, timidamente, desenvolver 
Ecoturismo étnico no Parque Nacional do Monte Pascoal: formas de comunicação entre condutores indígenas e visitantes da Unidade de Conservação.

eles. Esta liderança considera esta influência positiva, pois fortalece a etnia Pataxó na região e cria uma característica cultural e organizacional indígena local sobre o ecoturismo desenvolvido na região. Identificando esta influência, foi questionado sobre o risco dos atrativos e espaços turísticos Pataxó se tornarem iguais perdendo singularidade e diferenciais. O cacique respondeu: "[...] o Monte, a Mata e a história da aldeia Pé do Monte são únicas".

O grupo indígena que criou e organiza a Reserva Pataxó da Jaqueira foi pioneiro no ecoturismo étnico no Pólo Turístico do Descobrimento. A atividade para este grupo é a sua principal fonte de renda e meio de reproduzir e comunicar sua história e tradições aos diferentes agentes que interagem (LUÍNDIA, 2007).

A aldeia do Pé do Monte, de acordo com sua liderança, a partir de 2007 tenta se organizar em associação com intuito de conquistar uma maior autonomia na gestão da atividade turística no PNMP. O desejo é constituir um acordo formal com o ICMBio para efetuação de uma gestão indígena na visitação da UC.

De acordo com sua liderança a demarcação do território da aldeia se encontra em processo de negociação, o que dificulta a organização e o estabelecimento de ações continuadas no desenvolvimento do ecoturismo étnico no PNMP e na aldeia do Pé do Monte. Neste processo de negociação o movimento social Pataxó passa por um processo de fortalecimento nas arenas públicas, aonde vêm conquistando espaço e adquirindo voz ativa sobre as questões do direito ao território e suas formas de uso.

\section{Formas de comunicação popular Pataxó na visitação do PNMP}

A visitação no PNMP inicia na portaria com o contato do visitante com a etnia Pataxó, através do seu representante, chamado de condutor indígena (Figura 1). Durante a visitação este representante utiliza de pontos interpretativos para expressar, através de diferentes meios de comunicação, o seu contexto histórico e cultural e a relação antiga e atual com o ambiente natural da UC.

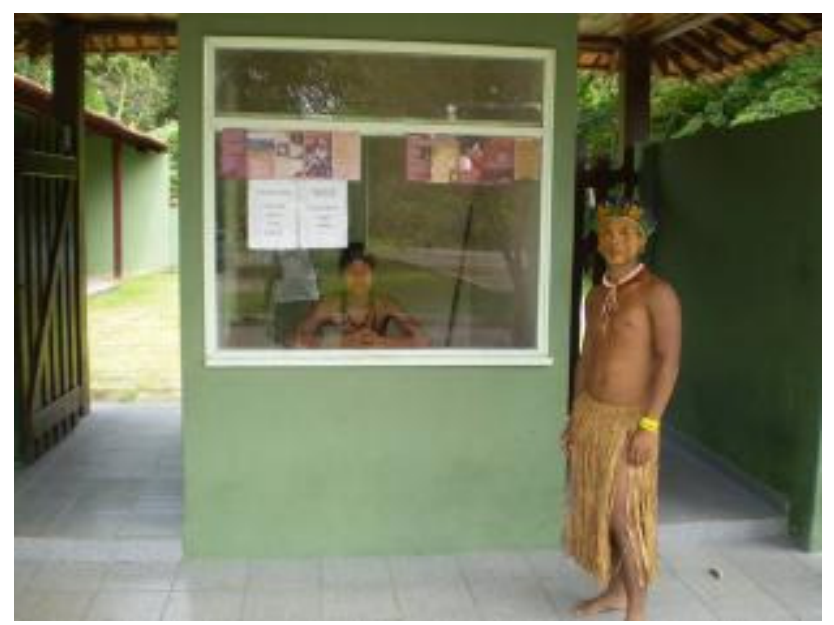

Figura 1: Condutores indígenas na portaria do PNMP. Foto: Carlos Alfredo Ferraz de Oliveira (2011). 
Durante o uso dos meios de comunicação, o condutor demonstra o objetivo de atrair e satisfazer o público e afirmar sua imagem étnica perante o "outro".

Na pesquisa foi observado o trabalho e os meios de comunicação destes condutores indígenas em diferentes pontos de visitação.

Segue a descrição dos dados por ponto de visitação:

\section{Monumento da Resistência}

Nesse ponto da visita, que dá acesso a todas as trilhas do PNMP, o condutor indígena, utilizando vestuário Pataxó, comunica verbalmente a história de luta e sobrevivência de sua etnia na região, iniciando com a chegada dos portugueses até os dias de hoje. Nessa narrativa, é apresentado o Monumento da Resistência como expressão do sentimento de diversas etnias indígenas do Brasil sobre os "500 Anos do Descobrimento". Afirma-se que, apesar da violência sobre suas culturas, os indígenas conseguiram sobreviver e retomar a área do PNMP, o que simboliza um marco do fortalecimento de sua etnia.

O Monumento da Resistência, construído pelos próprios índios no momento de retomada do PNMP, tem a forma do mapa do Brasil, fazendo uma junção com instrumentos usados pelos índios do Brasil - o maracá e a flecha. O mapa apresenta os nomes de diversas etnias indígenas do Brasil, localizadas em suas correspondentes regiões do país, demonstrando que já ocorreu presença indígena em todo território nacional e muitas delas ainda resistem e se fortalecem.

Os meios de comunicação popular são, neste ponto interpretativo, a arte plástica (monumento da resistência), vestuários tradicionais Pataxós e expressão verbal da história sóciocultural de uma etnia, envolvendo movimentos de lutas sociais indígenas (Figura 2).

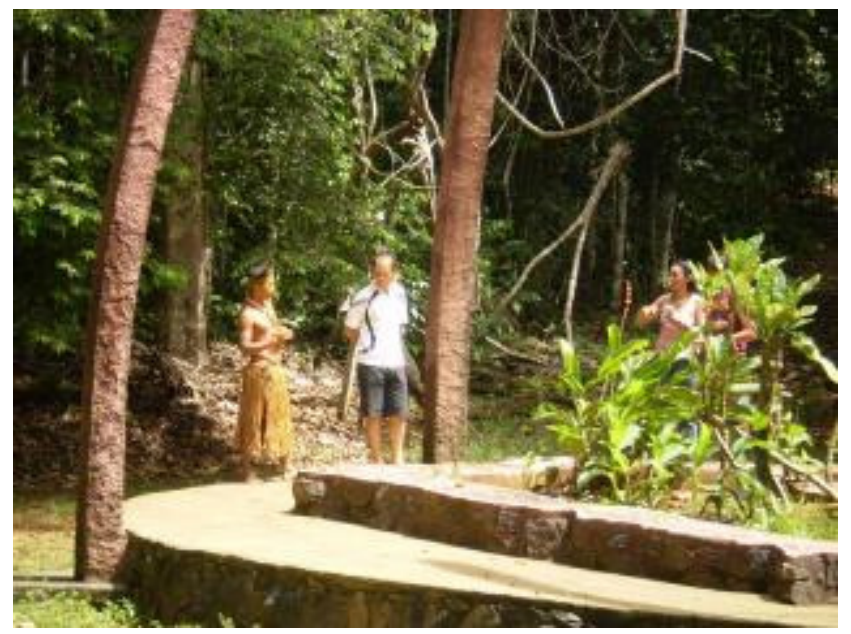

Figura 2: Condutor e turistas no Monumento da Resistência. Foto: Carlos Alfredo Ferraz de Oliveira (2011). 
Ecoturismo étnico no Parque Nacional do Monte Pascoal: formas de comunicação entre condutores indígenas e visitantes da Unidade de Conservação.

Foi identificado que existe um domínio maior da narrativa nos condutores mais veIhos. Os mais novos apresentam insegurança na fala demonstrando pouco domínio e pertencimento sobre sua história. Este fato provoca a hipótese que a transmissão oral das histórias e tradições pode está perdendo significado nas gerações mais jovens, podendo ocasionar transformações culturais indesejáveis pelos membros mais velhos, influenciando nas relações entre as gerações. Ressalta-se que a reprodução cultural e social desta comunidade depende da história oral.

\section{Trilha da subida do Monte}

A trilha ao cume do Monte Pascoal é o local mais procurado pelos visitantes do PNMP. Nessa trilha, o condutor não está obrigatoriamente utilizando vestuários tradicionais Pataxós.

O meio de comunicação utilizado pelos condutores é o verbal, em que são transmitidas informações das relações entre Pataxós com os elementos do ambiente e paisagem natural, utilizando nomes das árvores e às vezes dos fatos na língua Patxôhã. Quando não é compreendido pelo visitante, o condutor indígena explica o seu significado.

Não é abordado o contexto histórico de ser o primeiro monumento avistado pelas embarcações portuguesas como também o inicio do contato destes com o povo indígena. A mensagem é focada apenas sobre a importância da Mata Atlântica e da vista do Monte sob a ótica do índio Pataxó (Figura 3).

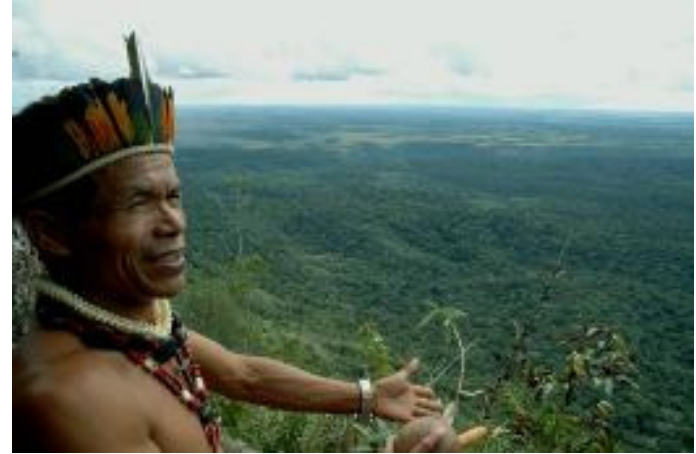

Figura 3: O Cacique Braga interpretando a paisagem no cume do Monte Pascoal. Foto: Helio de Castro Lima Rodrigues (2011).

Durante a trilha é abordado como no passado utilizavam a Mata Atlântica, através da caça e do extrativismo e que a partir da década de 1990, por razão do desmatamento, foi preciso mudar os formas de uso da área. A relação Pataxó e Mata Atlântica é o tema central da trilha.

\section{Artesanato Pataxó}

O artesanato Pataxó, durante a visita ao PNMP, é apresentado com finalidades comerciais e, ao mesmo tempo, como afirmação da identidade étnica. Algumas peças são produzidas em reservas indígenas da região, que utilizam dos recursos naturais existentes em seu território. 
A mensagem identificada no artesanato Pataxó é de uma mistura entre tradições antigas e novas na produção de apetrechos domésticos e de decoração. $O$ artesanato Pataxó vem recebendo influências externas diversas e constitui um meio de sobrevivência financeira e cultural. São produzidos arcos, flechas, colares, pulseiras e outros (Figura 4).

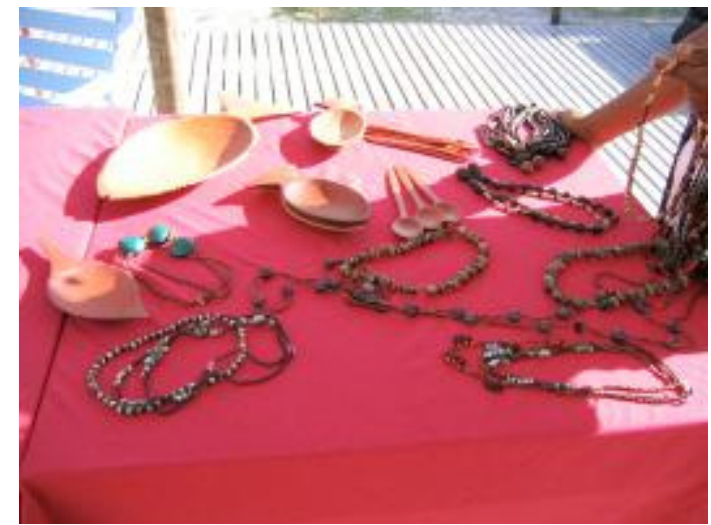

Figura 4: Artesanato Pataxó. Foto: acervo da RPPN Carroula.

\section{Ritual do Awê}

Outra forma de comunicação popular utilizada pelos condutores indígenas Pataxó é a representação do Awê aos visitantes. O Awê é um ritual tradicional dessa etnia. O local para representação do Awê é o Monumento da Resistência.

Para apresentação, os condutores participantes utilizam os vestuários tradicionais Pataxós. O condutor líder inicia dando uma breve explicação sobre a história de sua etnia e o significado do Monumento da Resistência. Explica que os Pataxós consideram o Awê, não como uma dança e música e sim como a celebração da alegria de estar unido, o que resulta na espiritualidade. O Awê é apresentado durante aproximadamente 20 minutos pelos Pataxós que posteriormente convidam os visitantes a participarem do ritual. Essa representação traz mensagens das características do movimento cultural e político Pataxó, mostrando, durante o ritual, sua língua, música, espiritualidade e dança (Figura 5).

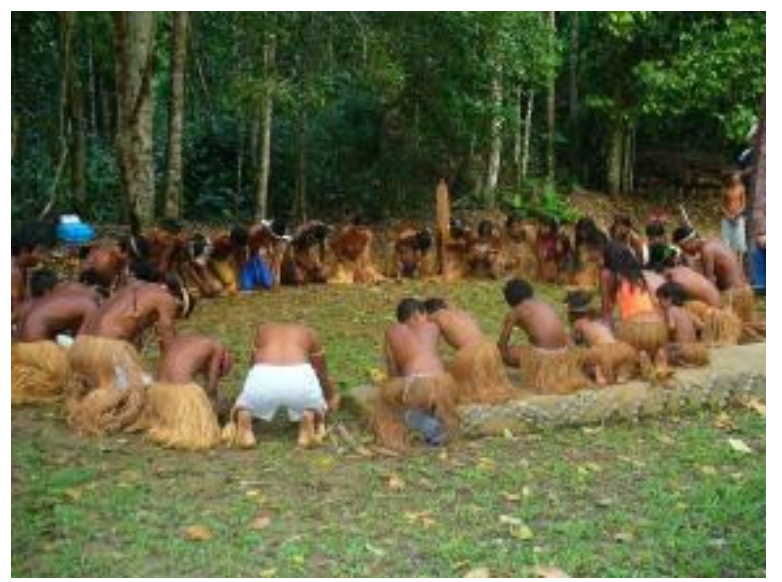

Figura 5: Apresentação do Awê na aldeia Pé do Monte. Foto: Helio de Castro Lima Rodrigues (2011) 
Ecoturismo étnico no Parque Nacional do Monte Pascoal: formas de comunicação entre condutores indígenas e visitantes da Unidade de Conservação.

suas tradições, manifestando sua voz social através de expressões como a música, a dança e o artesanato (CARVALHO, 2007).

Através do turismo étnico, os Pataxós vislumbram uma possibilidade de renda e de divulgação de suas tradições, principalmente através do artesanato, danças e conhecimentos sobre o ambiente natural. Este fato provoca o resgate de antigas e a criação de novas tradições (GRÜNEWALD, 2001).

De acordo com este autor (2001) o turismo étnico pode ser entendido sob duas perspectivas, uma em que o índio Pataxó e suas representações são o foco da viagem, e a segunda em que o motivo da viagem, por exemplo, é o Monte Pascoal e a Mata Atlântica, porém durante a visita irão observar e/ou vivenciar a etnia Pataxó e suas relações com o ambiente.

O tipo de turismo desenvolvido e realizado no PNMP pode ser considerado ecoturismo étnico, por se tratar de uma visitação a uma UC que envolve motivações de contato e vivências em áreas naturais e ao mesmo tempo com a etnia Pataxó. As finalidades do desenvolvimento da atividade nesta área são promover uma consciência ambiental e benefícios para a população indígena do entorno, como também o seu fortalecimento sociocultural.

A etnia pode ser entendida como elemento integrante de traços identitários culturais de grupos humanos (GANDINI, 2007). Todas as influências, muitas vezes impostas, que a etnia Pataxó sofreu, com certeza, resultaram em novas expressões, nas quais o turismo, como forma de organização socioeconômica, influenciou e influencia no resgate e na criação de novas tradições que são expressas nas arenas turísticas (GRÜNEWALD, 2001).

Para Handler e Linnekin (1984, p. 279, tradução nossa) "tradição é inventada porque é necessariamente reconstruída no presente". Uma tradição que é praticada a partir de uma manifestação cultural, sempre irá apresentar novas características e significados de acordo com as transformações socioculturais sofridas pelo grupo de quem a pratica (CARVALHO, 2007).

Em uma sociedade global, impulsionada pelas novas tecnologias de informação e comunicação, as expressões culturais sofrem, portanto, intera-ções, modificações - conscientes ou inconscientes - a partir da invenção de novos conceitos, da difusão de conceitos extraídos de outras culturas ou, ainda, a partir de descobertas realizadas pelos próprios integran-tes/participantes de determinada manifestação (CARVALHO, 2007, p. 64).

A comunicação popular de uma comunidade, neste caso os indígenas Pataxós da aldeia do Pé do Monte, é feita através de suas manifestações culturais tradicionais (antigas e/ou novas) e de sua luta pela melhoria de condições de existência (PERUZZO, 1995). Considerando as atividades turísticas no PNMP, esta comunica- 
ção é feita através da interpretação indígena do seu ambiente para os visitantes, o que também pode ser compreendida como a forma de interpretação ambiental utilizada nesta UC.

A interpretação ambiental de acordo com a definição de Tilden (1977, apud ALVES; FONTES; VITORINO, 2003, p.6) é a:

[...] revelação de significados e relações dos fenômenos do ambiente em linguagem entendível às pessoas comuns, pela experiência prática direta e por meios ilustrativos, não se limitando à simples comunicação de informações.

Autores como Murta e Albano (2002) e Vasconcelos (2003) abordam a interpretação ambiental como técnicas especiais de comunicação que visam provocar, cativar e estimular o visitante a interpretar os patrimônios naturais e/ou culturais visitados.

No contexto socioambiental do PNMP os fenômenos do ambiente relacionam os aspectos naturais e culturais de maneira integrada. Estes aspectos são revelados e traduzidos sobre a ótica indígena local que utiliza de suas manifestações culturais (técnicas especiais de comunicação) para proporcionar uma experiência prática e direta ao visitante da UC.

As manifestações culturais são compreendidas, neste trabalho, como o modo com que a comunidade Pataxó da aldeia do Pé do Monte expressa sua história de vida, crenças, costumes, ideias, anseios e percepções de si próprio e do ambiente em que vive (CARVALHO, 2007).

\section{Breve histórico da aldeia Pé do Monte}

O primeiro documento em que consta a presença indígena no litoral do extremo sul da Bahia é a carta de Pero Vaz de Caminha, narrando as suas impressões para o Rei Dom Manuel de Portugal, ao chegar no Brasil em 1500 (VAZ DE CAMINHA, 1974).

As primeiras décadas do século XIX, após os colonizadores terem exterminado os índios da etnia Tupi, os Pataxós foram reduzidos a povoações nas imediações das vilas costeiras do extremo sul da Bahia sofrendo repressões militares, através de submissão em trabalhos agrícolas (SAMPAIO, 2000). A repressão militar sobre os Pataxós e outras etnias que residiam na região, como os Maxakali, Botocudo, Kamakã, Tupiniquim de Trancoso e Vila Verde, obrigaram estes a se agruparem em uma única aldeia na faixa litorânea o que originou a aldeia de Barra Velha (CARVALHO, 1977). Provavelmente pela aldeia estar em território Pataxó e por estes estarem em maior número, o nome Pataxó prevaleceu entre as outras etnias presentes. Na época de 1860 até 1950, por razão do pouco contato que tiveram com agentes externos, denominados por eles como "brancos", os habitantes de Barra Velha reconstituíram seu 
Ecoturismo étnico no Parque Nacional do Monte Pascoal: formas de comunicação entre condutores indígenas e visitantes da Unidade de Conservação.

modo de vida (SAMPAIO, 2000).

Em 1951, por razão de um conflito entre policiais e Pataxós, provocados por agentes externos, a população indígena de Barra Velha fugiu para as cidades e fazendas vizinhas. Este acontecimento, que provocou mortes e violências sobre famílias inteiras de Pataxós, é conhecido e vivo em suas memórias até hoje como "fogo de 51". A dispersão desses indígenas ocasionou a construção de novas aldeias na região (SAMPAIO, 2000).

Em 1961 é criado pelo decreto federal $n^{\circ} 242$, o Parque Nacional do Monte Pascoal, em uma área 22.500 hectares (ha), ocupando todo o território da aldeia de Barra Velha e outras áreas ocupadas e utilizadas tradicionalmente pelos Pataxós. Após este decreto ocorreram conflitos, em que os indígenas não concordavam em sair do seu território. Durante a década de 1960 e 1970 o Instituto Brasileiro de Defesa Florestal - IBDF ${ }^{4}$, órgão na época responsável pelo parque, impedia os Pataxós de plantar suas roças, extrair alimentos como mariscos, caça e frutas. Esta repressão provocou miséria aos Pataxós ocasionando fome e doenças (SAMPAIO, 2000).

Em 1980, a FUNAI e o IBDF, chegaram ao um acordo no qual 8.627 ha do PNMP foram devolvidos para os Pataxós. Este fato minimizou os conflitos e problemas, mas não os resolveu. A maior parte desse território era arenoso e sem qualidade para produção agrícola, enquanto a população Pataxó vinha aumentando. Isso provocava a necessidade de um território maior para sua reprodução cultural, social, religiosa, ancestral e econômica (SAMPAIO, 2000).

A percepção de um tamanho insuficiente de território definido em 1980 levou à dispersão da população originária da Aldeia de Barra Velha para outros lugares, tanto para dentro do próprio PNMP, como para fora dele (LEITE, 1999).

Durante esses conflitos, as tradições Pataxós, que já tinham grande influência sobre as outras etnias que constituíam a aldeia de Barra Velha, enfraqueceram e se recriaram. $O$ artesanato sempre foi algo presente na cultura Pataxó. Através dele eram produzidos os utensílios do dia-a-dia. A repressão sobre o extrativismo, sofrida durante a implantação do PNMP, dificultou a manutenção e o desenvolvimento dessa prática. Com a criação de novas aldeias, a necessidade de renda e a construção da estrada federal BR 101 na região, os Pataxós, sob influências de turistas e comerciantes, recriaram sua produção artesanal, descobrindo elementos e técnicas novas, relacionando-as com a própria identidade (GRÜNEWALD, 2001).

Na década de 1990, a FUNAI, reconhecendo as irregularidades da demarcação da terra indígena de Barra Velha, constitui um grupo técnico para revisar os limites do território. Próximo ao período de comemoração dos "500 anos" da chegada dos portugueses, os índios Pataxós, através de um ato organizado por suas lideranças, com o apoio e presença de outras etnias indígenas, retomam uma área do PNMP, expulsando os funcionários do Instituto Brasileiro de Meio Ambiente e de Recursos Naturais Renováveis (IBAMA) ${ }^{5}$, e se instalando na entrada principal da UC. Após esse ato histórico Pataxó, foi feito um acordo de ajuste entre os Ministérios do Meio Ambiente e 
da Cultura, o IBAMA, a FUNAI e a comunidade indígena Pataxó, promovido pelo Ministério Público Federal. Esse acordo sugere a necessidade de uma gestão compartiIhada da UC (ISA, 2004).

Algumas famílias indígenas mantêm-se no entorno da portaria do PNMP e criam a aldeia do Pé do Monte, com o objetivo de conquistar o direito legal do seu território, de cuidar e apresentar os patrimônios naturais e culturais da área e reafirmar a história étnica Pataxó. Estes fatos caracterizam o nascimento e o fortalecimento de um movimento social Pataxó no extremo sul da Bahia, que tem como objetivo principal a garantia do direito ao território e o fortalecimento étnico deste povo.

Após diminuir os conflitos e estabelecer acordos institucionais entre os Pataxós, a FUNAI e o IBAMA, os integrantes da aldeia do Pé do Monte começam organizar a visitação do PNMP, a produção e a venda de artesanato, como forma de sustento e geração de renda. A área do Monte Pascoal é reconhecida em todo Brasil como marco histórico e de grande beleza cênica, o que faz atrair visitantes e turistas ao local e incentivar estas famílias indígenas a trabalharem com a visitação na UC.

O turismo no Parque é uma importante fonte de renda da aldeia, e também um jeito em que os condutores indígenas, conseguem contar a história e conhecimentos de $\mathrm{Pa}$ taxó (FERREIRA, comunicação pessoal ${ }^{6}$ ).

A liderança desta aldeia observa o ecoturismo étnico como uma importante atividade da aldeia. Através dela a comunidade identifica meios de acesso a renda e espaços para expressar seus elementos culturais e reafirmar sua etnia.

No desenvolvimento do ecoturismo étnico na aldeia, a liderança descreve que existiu apoio e influências externas para qualificação e organização da mão de obra local, como para instalação da infraestrutura necessária (trilhas e Centro de Visitantes). Sugere que o apoio continue e informa que existe um esforço coletivo e ainda tímido para construção de parcerias entre a aldeia, ICMBio, FUNAl e organizações não governamentais (ONG) socioambientais atuantes na UC.

A gestão desta atividade em 2008, 2009 e 2010 é feita pelo GTE. Durante a pesquisa foram identificadas limitações no seu poder de mobilização e participação dos envolvidos. Ressalta-se que é primordial, para que ecoturismo se torne uma ferramenta para sustentabilidade em um território que envolve diferentes agentes, a construção do espaço que possibilite diálogos transparentes entre os envolvidos, participação gestora e deliberativa, consideração das diferentes lógicas e pontos de vista existentes (OLIVEIRA, 2011).

De acordo com o cacique da aldeia as formas de organização do ecoturismo étnico na aldeia do Pé do Monte e no PNMP, apresentam influência direta da Reserva Pataxó da Jaqueira, área que pertence a aldeia urbana de Coroa Vermelha, por razão do seu pioneirismo na organização da atividade e dos intercâmbios realizados entre 
Ecoturismo étnico no Parque Nacional do Monte Pascoal: formas de comunicação entre condutores indígenas e visitantes da Unidade de Conservação.

\section{Considerações finais}

Considerando a história sociocultural dos índios Pataxós no litoral do extremo sul da Bahia percebe-se a construção e crescimento de um movimento social indígena, com o objetivo de reconquistar o seu território. A retomada do PNMP simboliza esse movimento. A comunicação do condutor indígena representa esses fatos, através da narrativa, do artesanato, da arte plástica e do Awê. A narrativa apresenta o ponto de vista indígena sobre a história do Brasil, especialmente de seu "descobrimento", como também sua relação anterior e atual com a Mata Atlântica. O artesanato manifesta aspectos do cotidiano da cultura indígena. E finalmente, o ritual do Awê faz o turista experienciar uma vivência cultural pataxó.

Nos resultados da pesquisa identifica-se que os condutores indígenas da aldeia do Pé do Monte realizam a comunicação popular expressando suas características e tradições para turistas e/ou visitantes do PNMP. Este fato pode corresponder uma nova afirmação da cultura deste povo, que através do ecoturismo étnico encontram formas de comunicar com outros grupos sociais.

De acordo com Renó (2007) os "agentes folkcomunicacionais" são os "líderes de opinião" de uma comunidade, que informam mensagens transmitidas pela mídia influenciando o entendimento de seus liderados. Os condutores indígenas podem ser compreendidos como "agentes folkcomunicacionais" que além de suas influências na comunidade, informam e provavelmente influenciam visitantes e turistas sobre a história e cultura do índio Pataxó no extremo sul da Bahia.

O Turismo, assim como outros fatores, provocou alterações nos Pataxós da aldeia do Pé do Monte sobre os aspectos culturais, dentre as quais foi a criação de um espaço para invenção e afirmação de suas tradições oportunizando a expressão dos seus velhos e novos símbolos.

O processo de criação do PNMP, como outras Unidades de Conservação no Brasil, principalmente de proteção integral, não considerou a importância sociocultural de grupos humanos que utilizavam a área da UC como seu território, prejudicando inclusive a conservação da biodiversidade. A partir de 2001 a nova gestão do PNMP teve que envolver a comunidade indígena do Pé do Monte nas tomadas de decisões sobre a UC, inclusive sobre as atividades de uso público, o que configura o início de uma conquista dos Pataxó sobre este território podendo resultar em melhoras socioambientais para o Parque e para a aldeia do Pé do Monte.

O ecoturismo étnico vem se tornando uma ferramenta que configura este novo momento, e traz possibilidades de integrar dimensões da sustentabilidade como econômico, social, ambiental, cultural e político, como foi demonstrado nos dados descritos. 


\section{Referências Bibliográficas}

ALVES, S.C.; FONTES, M.A.L.; VITORINO, M.R. Ecoturismo e interpretações. Lavras: UFLA/FAEPE, 2003. 73p.

BRASIL. Diretrizes para uma política nacional de ecoturismo. BARROS.M.S; PENHA.L.H.D (coord). Brasília: EMBRATUR e MICT/MMA, 1994. 48p.

CARVALHO, M.R.G. Os Pataxós de Barra Velha: seu subsistema econômico. 1977. 207f. Dissertação (Mestrado) - Programa de Pós-Graduação em Antropologia. Universidade Federal da Bahia. Salvador, 1977.

CARVALHO, S.V.C.B. Rocha. Manifestações Culturais. In: GADINI, S. L; WOLTOWICZ, K. J. (org.) Noções básicas de folkcomunicação. Ponta Grossa: UEPG, p. 64-66, 2007.

GADINI, S. L. Expressões Étnico-Culturais. In: GADINI, S.L.; WOLTOWICZ, K.J. (org.) Noções básicas de folkcomunicação. Ponta Grossa: UEPG, p. 121-123, 2007.

GIL, A. C. Métodos e técnicas de pesquisa social. São Paulo: Atlas, 1987. 206p.

GRÜNEWALD, R. A. Os índios do Descobrimento: tradição e turismo. Rio de Janeiro: Contra capa livraria, 2001.

HANDLER, R; LINNEKIN, J. Tradition, genuine or spurious. Journal of American Folklore. [S.I.: s.n.]. v. 97, n³85, p. 273-290, 1984.

INSTITUTO SOCIOAMBIENTAL - ISA. Para Criar um Programa para a Proteção e o Uso Sustentável da Biodiversidade em Terras Indígenas. São Paulo: Mimeo, 2004. 77p.

JONES, P. Studying society: sociological theories and research pratices. Londres: Collins, 1993. 182p.

LEITE, J. C. F. Projeto geopolítico e terras indígenas: dimensões territoriais da política indigenista. 1999. 197f. Dissertação (Mestrado) - Programa de Pós-Graduação em Geografia. Universidade Federal do Rio de Janeiro. Rio de Janeiro, 1999.

LUÍNDIA, A. L. Ecoturismo indígena. Quito - Equador: Abya -Yala, 2007. 216p.

MINAYO, M. C. S. O desafio do conhecimento: pesquisa qualitativa em saúde. $8^{\circ}$ ed. São Paulo: Hucitec, 2004. 269p.

MURTA, S. M. M; ALBANO, C. (org). Interpretar o patrimônio: um exercício do olhar. Belo Horizonte: Ed. UFMG; Território Brasillis, 2002. 288p.

OLIVEIRA. C, A. F. Relatório técnico final de ecoturismo no Parque Nacional do Monte Pascoal. Brasília: PNUD/PCE, 2008. 33p.

OLIVEIRA. C, A. F. Comunidades ribeirinhas da Reserva Extrativista Cassurubá, Caravelas Bahia: perspectivas para construção participativa do ecoturismo de base comunitária. 2011. 214f. Dissertação (Mestrado) - Programa de Pós-Graduação em Cultura e Turismo. Universidade Estadual de Santa cruz. Ilhéus. 2011.

PERUZZO, C. M. K. Comunicação popular em seus aspectos teóricos. In: PERUZZO, C. M. K. (org). Comunicação e culturas populares. São Paulo: Intercom, p. 27-44, 1995. 
Ecoturismo étnico no Parque Nacional do Monte Pascoal: formas de comunicação entre condutores indígenas e visitantes da Unidade de Conservação.

PRODETUR NE II. Plano de Desenvolvimento Integrado do Turismo Sustentável - Costa do Descobrimento. São Paulo: Fundação Getúlio Vargas.; HVS International.; Governo do Estado da Bahia, 2002. 238p.

RENÓ, D. P. Agentes de folkcomunicações. In: GADINI, S. L; WOLTOWICZ, K. J (Org.) Noções básicas de folkcomunicação. Ponta Grossa: UEPG, p. 44 - 46, 2007.

SAMPAIO, J. A. L. Breve história da presença indígena no extremo sul baiano e a questão do território Pataxó do Monte Pascoal. In: XXII Reunião brasileira de antropologia. Anais. Fórum de pesquisa 3: "Conflitos socioambientais e Unidades de Conservação". Brasília, 2000. 19p.

STACEY, M. Methods of social research. Oxford: Pergamon, 1977. 173p.

VASCONCELOS, J. M. O. Interpretação ambiental. In: MITRAUD, S. (coord). Manual de ecoturismo de base comunitária: ferramentas para um planejamento responsável. Brasília: WWF, p. $261-294,2003$.

VAZ, C. P. Carta a El-Rei Dom Manuel sobre o Achamento do Brasil. Lisboa: Imprensa Nacional/Casa da Moeda, 1974 [1500]. 45 p.

\section{Notas}

${ }^{1}$ Município turístico, localizado no extremo sul da Bahia, que faz parte do Pólo Turístico do Descobrimento, área prioritária para o desenvolvimento do Turismo no Brasil (PRODETUR NE II , 2002).

${ }^{2}$ Segmento turístico realizado em patrimônios naturais e culturais, que incentiva sua conservação e a formação de uma consciência ambientalista, promove o bem-estar das populações envolvidas (BRASIL, 1994, p. 19).

${ }^{3}$ De acordo com Sampaio ( 2000) o "fogo de 51" é percebido na memória dos Pataxó como um conflito entre eles e policiais militares da região em 1951 na aldeia de Barra Velha. Este conflito ocasionado, de acordo com a versão Pataxó, pelo um "mal entendido", resultou na violência e morte de alguns índios e favoreceu o processo de perda de suas terras.

${ }^{4}$ Órgão federal já extinto.

${ }^{5}$ IBAMA na época era o órgão responsável pela gestão e manejo da UC.

${ }^{6}$ Fornecida, através de entrevista, pelo Osiel Santana Ferreira (Araçaí, Braga), cacique da aldeia do Pé do Monte.

Carlos Alfredo Ferraz de Oliveira: Instituto Superior de Educação e Cultura Ulysses Boyd, ISECUB, Vitória, ES, Brasil.

Email: cferrazgp99@yahoo.com.br

Link para o currículo Lattes: http://lattes.cnpq.br/1561110382196376

Data de submissão: 30 de outubro de 2011

Data de recebimento de correções: 08 de janeiro de 2012

Data do aceite: 08 de janeiro de 2012

Avaliado anonimamente 